\title{
The Procyclical Role of Rating Agencies: Evidence from the East Asian Crisis
}

\author{
G. Ferri, L.-G. Liu and J. E. Stiglitz*
}

We demonstrate that credit rating agencies aggravated the East Asian crisis. In fact, having failed to predict the emergence of the crisis, rating agencies became excessively conservative. They downgraded East Asian crisis countries more than the worsening in these countries' economic fundamentals would justify. This unduly exacerbated, for these countries, the cost of borrowing abroad and caused the supply of international capital to them to evaporate. In turn, lower than deserved ratings contributed - at least for some time - to amplify the East Asian crisis. Although this goes beyond the scope of our paper, we also propose an endogenous rationale for rating agencies to become excessively conservative after having made blatant errors in predicting the East Asian crisis. Specifically, rating agencies would have an incentive to become more conservative, so as to recover from the damage these errors caused to them and to rebuild their own reputation.

\section{Introduction}

Credit rating agencies play an important role in financial markets. Their main output consists of assigning credit ratings to sovereign and private sector borrowers throughout the world. Financial markets rely on rating agencies, also, for constantly updating the credit ratings they have assigned to issuers (Cantor and Packer, 1994). These ratings offer financial markets an estimate of the probability that borrowers will not fulfil the obligations specified in their debt issues. The higher the rating, the lower is such probability, and vice versa. Accordingly, issuers with lower ratings must pay higher interest rates embodying larger risk premia - than higher-rated issuers. Furthermore, besides affecting the cost at which issuers can borrow, ratings determine the extent of potential investors. Specifically, statutes and regulations either forbid institutional investors to invest in assets carrying ratings below a certain level

* We would like to thank Jason Furman, Charles Goodhart, Ronald McKinnon and other participants in the Siena Conference as well as Himmat Kalsi and Ashoka Mody for very helpful suggestions. We also thank Noemi Lea Giszpenc for excellent research assistance.

C) Banca Monte dei Paschi di Siena SpA, 1999. Published by Blackwell Publishers, 108 Cowley Road, Oxford OX4 1JF, UK and 350 Main Street, Malden, MA 02148, USA. 
or they require extra capital to be posted (Dale and Thomas, 1991): These assets are referred to as 'below-investment-grade' or 'speculative' assets. Thus, when an issuer receives a rating below-investment-grade, the extent of potential investors significantly shrinks. In practice, such issuer will no longer face the demand from all investors. As for institutional investors, the legal restriction becomes now binding, the below-investment-grade issuer will have to rely on only the small fraction of investors to which such restriction does not apply.

Given the large economies of scale - in processing the information to assign ratings - and the needed reputation - which takes a long time to build - the credit rating industry is highly concentrated and new entries are hardly observed. There are only three rating agencies performing a significant world activity: Moody's, Standard \& Poor (S\&P) and Fitch-IBCA. The first two are US companies, the third is a UK-US company. Moody's was the first rating agency: it published its first rating in 1909, while S\&P did it in 1923. FitchIBCA is the result of a recent merger whereby in 1997 IBCA - a UK rating agency specialized in rating banks which started publishing ratings in $1978-$ acquired control of Fitch - a US company specialized in structured finance whose first rating was published in 1922. In general, ratings assigned to the same borrower do not differ substantially across rating agencies (Cantor and Packer, 1997). Furthermore, all rating agencies tend to change their outlook on a borrower more or less at the same time.

In 1997 and 1998, many observers pointed out that rating agencies had failed to preventively warn the markets against the East Asian crisis. International financial institutions unanimously blamed rating agencies for their inability to forecast the East Asian crisis (BIS, 1998; IMF, 1998; World Bank, 1998). Rating agencies acknowledged having made mistakes and tried to justify their mistakes (Fitch-IBCA, 1998; Truglia, 1998). Specifically, they claimed that the East Asian crisis had different features with respect to the past: differently from other previous crises, in East Asia, public finances were in order and there were private sector problems to trigger a crisis for sovereign borrowers. The novelty of the crisis - rating agencies claim - made it impossible to forecast it for rating agencies that based their outlook on statistical models not yet accounting for private sector vulnerabilities.

As the crisis became full blown, rating agencies downgraded the sovereign ratings of Indonesia, Korea and Thailand all below-investment-grade. We demonstrate that rating agencies became excessively conservative. Specifically, they downgraded East Asian crisis countries more than the worsening in these countries' economic fundamentals would justify. Such rating agencies' actions unduly exacerbated, for these countries, the cost of borrowing abroad and caused the supply of international capital to them to evaporate. In turn, lower than deserved ratings contributed - at least for some time - to amplify the East Asian crisis. We argue that rating agencies, having failed to predict the emergence of the crisis, had an incentive to become more conservative, so as 
to recover from the damage these errors caused to them and to rebuild their own reputation.

The rest of this paper is structured as follows. In the next section, we synthesize the discussion on the rating agencies' failure to warn the markets before the East Asian crisis. We argue that, in the face of such failure, rating agencies may have had an incentive to become overly conservative. In turn, this may have aggravated the East Asian crisis. In section 3, we discuss our methodology, lay out the hypotheses to be tested and comment on the results of our econometric exercise. Section 4 discusses why rating agencies may have an incentive to assign procyclical ratings. Section 5 concludes.

\section{Rating Agencies and the East Asian Crisis: Downgrading Too Late and Too Much?}

Credit rating agencies were caught by surprise by the East Asian crisis. Table 1 reports the sovereign rating history up to the crisis for Indonesia, Korea, Malaysia and Thailand according to the ratings assigned to these countries by Moody's, S\&P, and Fitch-IBCA.

Downgradings were performed only in December 1997 for Indonesia and Malaysia. Korea was downgraded in October/November 1997. Moody's downgraded Thailand at the beginning of April - on April 8, 1997 as the crisis was simmering, but S\&P did not downgrade Thailand until September 3, 1997, well into the crisis. Except for Malaysia, all the countries were downgraded from investment to below-investment-grade. In fact, referring to Moody's only, Malaysia was downgraded by four notches (from A1 to Baa2). Thailand was downgraded five notches (from A2 to Baa3). The largest downgradings (six notches) were for Indonesia and Korea: respectively from $\mathrm{Baa} 3$ to $\mathrm{Caa} 3$ and from A1 to Ba1. Needless to say, downgradings of this size are extremely unusual, and were decided late in the crisis.

External observers had the impression that rating agencies were judging that a general meltdown in these economies was happening. However, it was difficult from outside to tell how much rating agencies themselves, with their decision, were contributing to the perspective of such meltdown. It may be important to compare what happened to credit ratings during the East Asian crisis and during previous major crises.

\subsection{Comparing the Response of the Ratings to the Mexican and to the East Asian Crisis}

The specific question worth addressing is how the downgradings following the East Asian crisis compare with rating revisions after the previous major crisis, the Mexican crisis. First, referring to Moody's ratings, we convert them 
Table 1: Sovereign Rating History for East Asian Crisis Countries

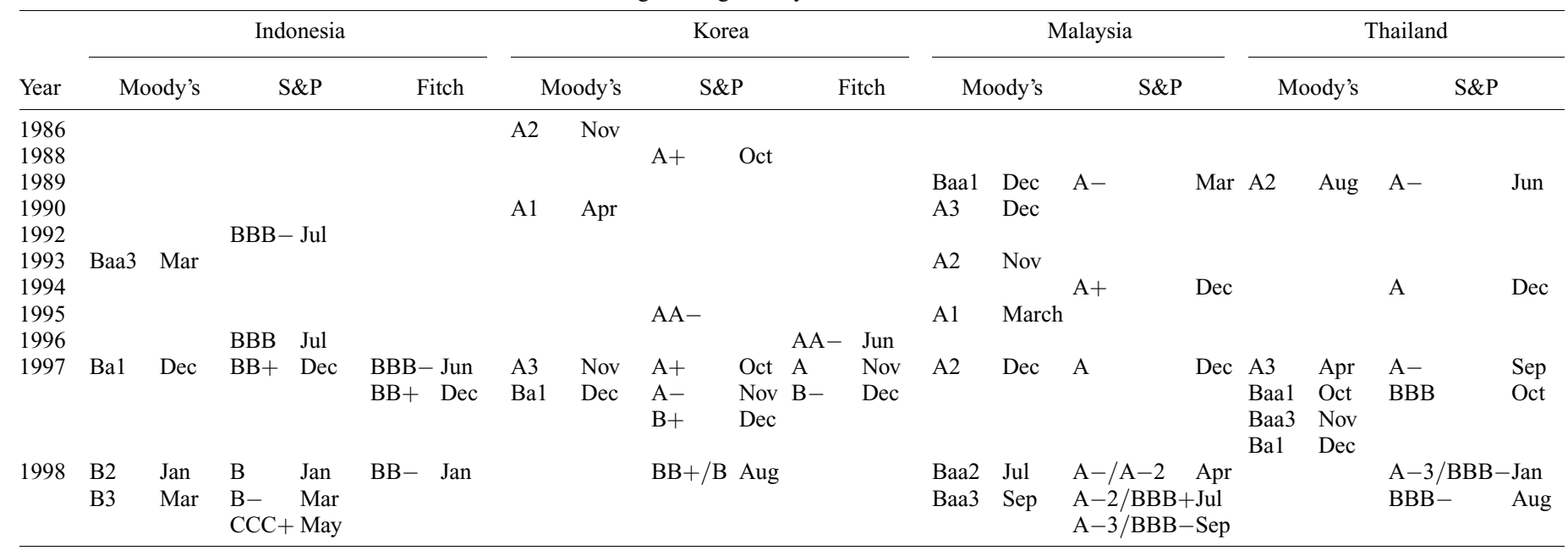

(C) Banca Monte dei Paschi di Siena SpA, 1999. 
from an alphanumeric into a numeric format according to the following correspondence shown in column 2 of Table 2.

Then, on the basis of this linear conversion, Figure 1 shows rating revisions between 1994 and 1995. Figure 1 reports on the $x$-axis the (minimum) rating for each country in 1994 - the pre-crisis status - and contrasts it with the (minimum) rating for that country in 1995 - the post-crisis status reported on the $y$-axis. Points lying below the $45^{\circ}$ line identify those countries suffering a downgrading between 1994 and 1995; points lying on the $45^{\circ}$ line refer to those countries whose rating did not change; points above the $45^{\circ}$ line identify those countries whose rating improved between 1994 and 1995.

Three aspects are worth emphasizing. First, downgradings and upgradings were more or less balanced: while four countries were downgraded, five countries were upgraded. Second, downgradings and upgradings were observed for both high-rating countries (Canada, and Sweden downgraded; Ireland, and New Zealand upgraded) and low-rating countries (Mexico, and Pakistan downgraded; Brazil, the Czech Republic, and India upgraded). Third, no investment-grade country became below-investment-grade: even Mexico, suffering the harshest downgrading from $\mathrm{Baa} 1 / \mathrm{Ba} 3$ (or 52.5) to $\mathrm{Ba} 2 / \mathrm{Ba} 3$ (or 42.5 ), did not change status since it was not an investment-grade country before the crisis. Equivalently, we may notice that no points appear in the second - the South-East one - of the four quadrants delimited by the two dotted lines for investment-grade in 1994 and investment-grade in $1995 .{ }^{1}$

The picture is quite different looking at the East Asian crisis. Using the same technique as in Figure 1, Figure 2 reports on the $x$-axis the (minimum) rating for each country in 1996 - the pre-crisis status - and contrasts it with the (minimum) rating for that country in 1998 - the post-crisis status reported on the $y$-axis.

We still refer to the three aspects emphasized above. Even though downgradings and upgradings were more or less balanced in number (11 countries downgraded, 10 countries upgraded), the average size of the downgrades by far outweighed the average size of the upgrades. Second, substantive downgradings were observed only for low-rating countries, with the only exception for the three East Asian mid-high rated crisis economies (Korea, Malaysia, and Thailand), while upgradings were mostly concentrated within the group of high-rating countries. Third, five countries are in the second quadrant (India, Indonesia, Korea, Slovakia, and Thailand) whereas only one is in the fourth quadrant (Hungary). More specifically, India and Slovakia cross the dotted line

1 The first (North-East) quadrant identifies countries whose rating was above-investmentgrade both before and after the crisis. The second (South-East) quadrant identifies countries whose rating was above-investment-grade before the crisis but has become below-investment-grade after the crisis. The third (South-West) quadrant identifies countries whose rating was below-investmentgrade both before and after the crisis. The fourth (North-West) quadrant identifies countries whose rating was below-investment-grade before the crisis but has become above-investment-grade after the crisis. 
Table 2: Converting Moody's Alphanumeric Ratings into Numeric Values

\begin{tabular}{lccc}
\hline & Linear conversion & $\begin{array}{c}\text { Nonlinear conversion } \\
\text { (Calm period) }\end{array}$ & $\begin{array}{c}\text { Nonlinear conversion } \\
\text { (Turbulent period) }\end{array}$ \\
\hline Aaa & 100 & 100.0 & 100.0 \\
$\mathrm{Aa} 1$ & 95 & 98.7 & 99.1 \\
$\mathrm{Aa} 2$ & 90 & 97.0 & 98.0 \\
$\mathrm{Aa} 3$ & 85 & 95.2 & 96.9 \\
$\mathrm{~A} 1$ & 93.2 & 95.6 \\
$\mathrm{~A} 2$ & 80 & 91.7 & 95.2 \\
$\mathrm{~A} 3$ & 75 & 89.3 & 86.4 \\
$\mathrm{Baa} 1$ & 70 & 87.1 & 85.8 \\
$\mathrm{Baa} 2$ & 65 & 84.4 & 85.2 \\
$\mathrm{Ba} 3$ & 60 & 79.5 & 71.1 \\
$\mathrm{Ba} 1$ & 55 & 75.0 & 59.3 \\
$\mathrm{Ba} 2$ & 50 & 65.4 & 40.9 \\
$\mathrm{Ba3}$ & 45 & 56.9 & 32.9 \\
$\mathrm{~B} 1$ & 40 & 54.3 & 30.9 \\
$\mathrm{~B} 2$ & 35 & 33.8 & 25.0 \\
$\mathrm{~B} 3$ & 30 & 25.0 & \\
$\mathrm{Caa} 1$ & 25 & & \\
$\mathrm{Caa} 2$ & 20 & & \\
$\mathrm{Caa} 3$ & 15 & & \\
$\mathrm{Caa}$ & 10 & 5 & \\
\hline
\end{tabular}

suffering relatively small downgrades (respectively from Baa3 or 55 to Ba1 or 50 and from $\mathrm{Baa} 3$ or 55 to $\mathrm{Ba} 2$ or 45) while Indonesia, Korea, and Thailand experience major negative revisions (respectively from $\mathrm{Baa} 3$ or 55 to $\mathrm{B} 3$ or 25 , from $\mathrm{A} 3$ or 80 to $\mathrm{Ba} 1$ or 50 , and from $\mathrm{A} 2$ or 75 to $\mathrm{Ba} 1$ or 50 ).

All in all, the shape of Figure 2 appears consistent with a 'flight to quality' in credit ratings. On the one hand, low-rating countries tend to suffer downgradings; on the other hand, highest-rating countries experience stable or improving ratings. Once more, this will worsen the situation for low- and midrated countries in three ways.

First, lower ratings increase the cost of funds. Two examples may suffice. Regressing a cross-section of 35 sovereign interest rate spreads observed in the fall of 1995 on those countries' contemporary ratings, Cantor and Packer (1996) can explain 92 per cent of the variance of those ratings. Moody's (1994) computes, for end October 1994, the median yields by rating (adjusted to 7year maturity) and finds that yields increase from 8 per cent for Aaa to 13 per cent for $\mathrm{Caa}^{2}$

Second, the increase in the cost of funds is particularly traumatic when the country becomes below-investment-grade. Moody's (1994) reports that yields are relatively insensitive to downgradings as long as the rating stays aboveinvestment-grade, while yields become very responsive to even small down-

2 See Hand, Holthausen, and Leftwich (1992) for a structured analysis of the impact of rating changes on asset prices. 


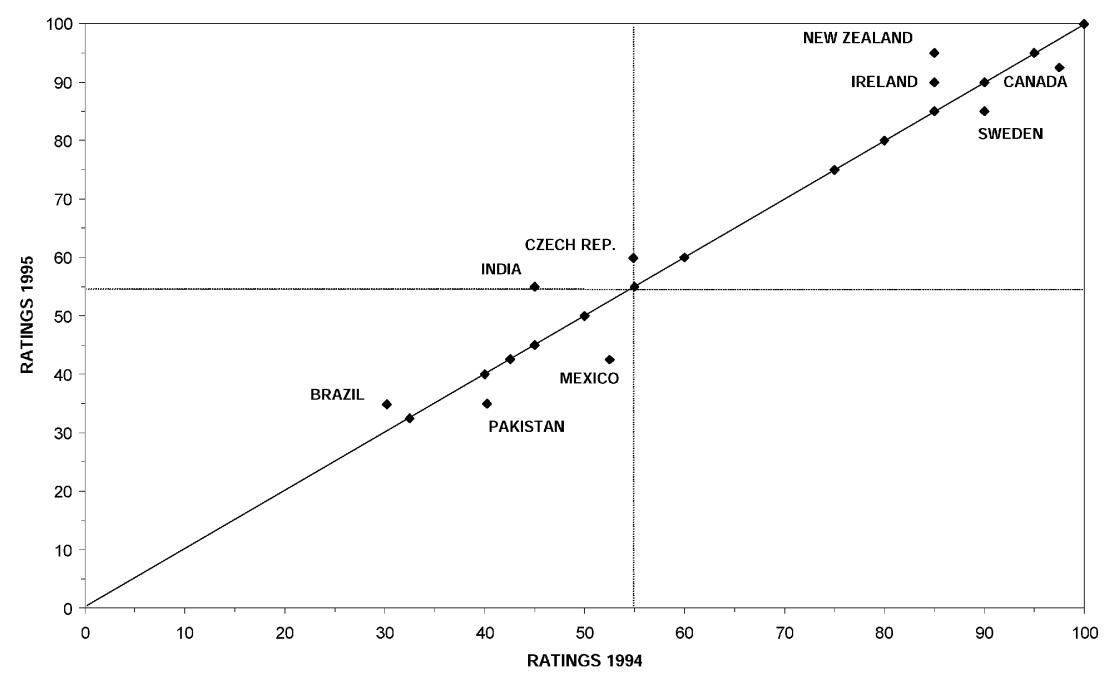

Figure 1: The Impact of the Mexican Crisis: Ratings in 1995 vs 1994

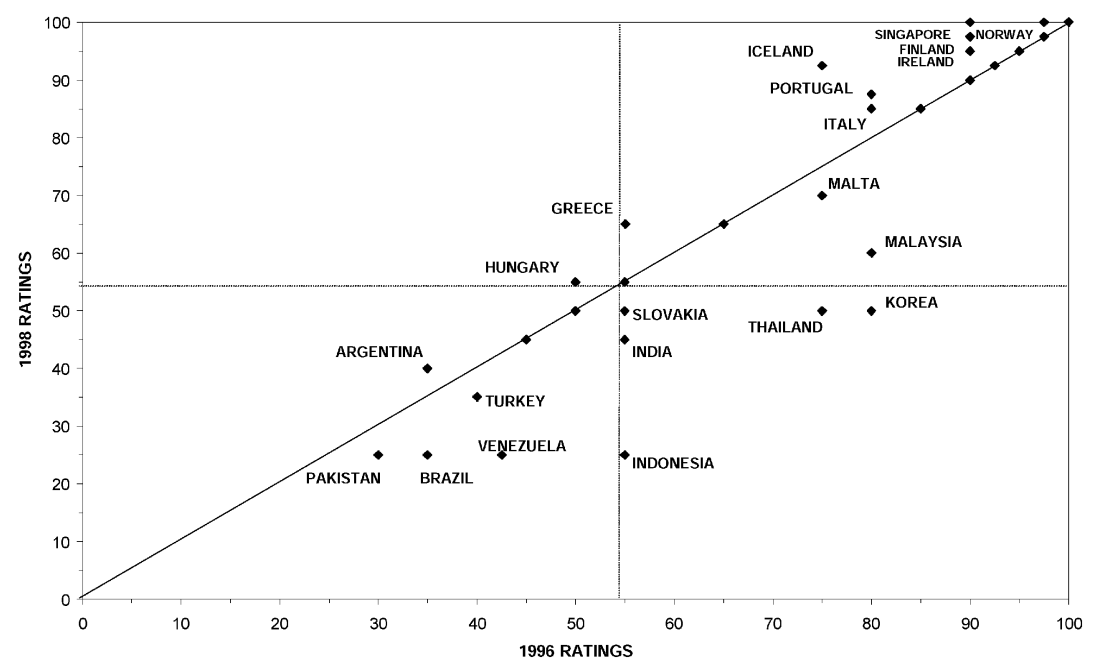

Figure 2: The Impact of the East Asian Crisis: Ratings in 1998 vs 1996

gradings when the rating plunges below-investment-grade. For instance, it takes 8 notches rating drops (from Aaa-rated to Baa3-rated securities, i.e. when the rating drops from 100 to 55) to cause yields to increase by 100 basis points (from 8 to 9 per cent) while it takes only two notches downgrading (from Baa3 to $\mathrm{Ba} 2$, or from 55 to 45 ) to increase the yield by an additional 100 basis points (from 9 to 10 per cent). Eight additional notches of downgrading (from $\mathrm{Ba} 2$ to $\mathrm{Caa}$, or from 45 to 5) raise the yield further by 350 basis points. 
Third, in addition to substantially increasing the cost of funds, being downgraded to below-investment-grade may lead to quantity rationing. In fact, regulations either prohibit institutional investors to hold below-investmentgrade securities or generally require that extra capital be held against these securities (Cantor and Packer, 1997; Dale and Thomas, 1991).

These observed patterns about the relation between ratings and interest rate spreads strongly suggest that such relation may be nonlinear. To obtain a more accurate measurement of this relation, we therefore used secondary market interest rate spreads on emerging economies sovereign bonds of equivalent maturity issued in USD. Furthermore, this relation could itself be quite different during a period of crisis with respect to a 'calm' period. ${ }^{3}$ Thus, whereas column 2 of Table 1 is a linear cardinalization of the ratings, columns 3 and 4 report a nonlinear conversion into numeric ratings to 'let the market' provide the cardinalization during a calm period and a crisis period, respectively.

Specifically, we let the basis premium provide a 'numeric' equivalent to the ratings through the following calculation. As we move down along the observed range of ratings - AAA (or 100 in the linear conversion) to B3 (or 25) - for each single notch of downgrading, we compare the relative increase in the spread to the total increase in the spread over the entire range. For each single notch of downgrading, this provides us with the weight measuring the relative importance of being downgraded by that very notch. Then, we apply this weight to the 5-point reduction in the numeric rating that should apply according to the linear model. If the weight is much below (above) unity, then being downgraded by that very notch has little (a great) bearing on the spread, and we calculate a reduction in the numeric rating much lower (higher) than the 5-point one of the linear model.

In practice, the calculation we just described is obtained through the following formula delivering the nonlinear conversion of the ratings:

$$
N L R_{i}=N L R_{i-1}-5 \times\left(\frac{S P R_{i}-S P R_{i-1}}{S P R_{15}}\right)
$$

where $i=1,2, \ldots, 15$ spans from 95 to 25 according to the linear model, and $N L R_{0}=L R_{0}=100$. We should also notice that $N L R_{15}$, corresponding to 25 is effectively equal to 25 : thus, the nonlinear transformation is simply a spanning of the original ratings over the same range.

From Figure 3, it is easy to appreciate how this nonlinear conversion relates to the linear one. It is worth noting that the slope of the relation increases as we move from higher to lower ratings. In particular, in line with

3 As earlier data were unavailable, we took the pre-crisis average of the spreads over the period January-March 1997 while crisis-period spreads were measured over the period November-December 1997. We could observe these spreads for 15 emerging countries: Argentina, Brazil, China, Colombia, Croatia, Indonesia, Malaysia, Mexico, Pakistan, Philippines, Romania, South Africa, Thailand, Turkey, Uruguay. Russia was excluded because it was a clear outlier. 


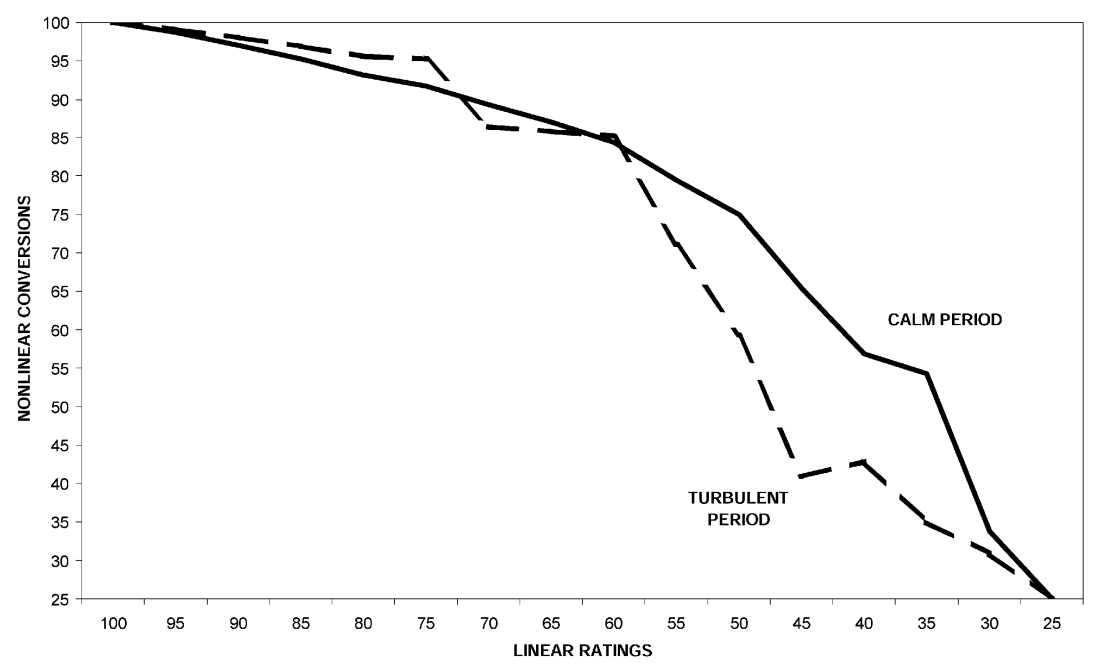

Figure 3: Relation Between Linear and Nonlinear Conversions of the Ratings

our reasoning above, the first major increase in the slope occurs when we go from above to below-investment-grade. Furthermore, the spreads show this threshold is very sensitive during the turbulent (crisis) period.

In addition to causing an increase in the cost of funds, more generally severe downgradings give a negative signal on the country being downgraded to market participants. Accordingly, consequences may attain also to the exchange rate, to the stock market, and to the value of other domestic assets. Thus, the perspective meltdown of the economy may even become a self-fulfilling prophecy.

Indeed, after the downgrading the yield spread of East Asian crisis countries' bonds denominated in USD with respect to US Treasury bonds of equivalent maturity significantly rose. This is shown in Figure 4 which refers to Indonesia, Malaysia, and Thailand. ${ }^{4}$

Although it is not easy to ascertain a causal relationship visibly from these graphs, we can refer to the results of Reisen and von Maltzan (1999) who show that rating changes Granger-caused yield spreads in the East Asian crisis.

\section{Methodology and Econometric Results: Excessive Downgrading in East Asia}

\subsection{Rating Agencies' Model}

Although the rating agencies never disclose their quantitative methodology on how they assign sovereign ratings, they do occasionally reveal their

4 The graph cannot be drawn for Korea, which had no bonds outstanding before the crisis. 


\section{Indonesia}
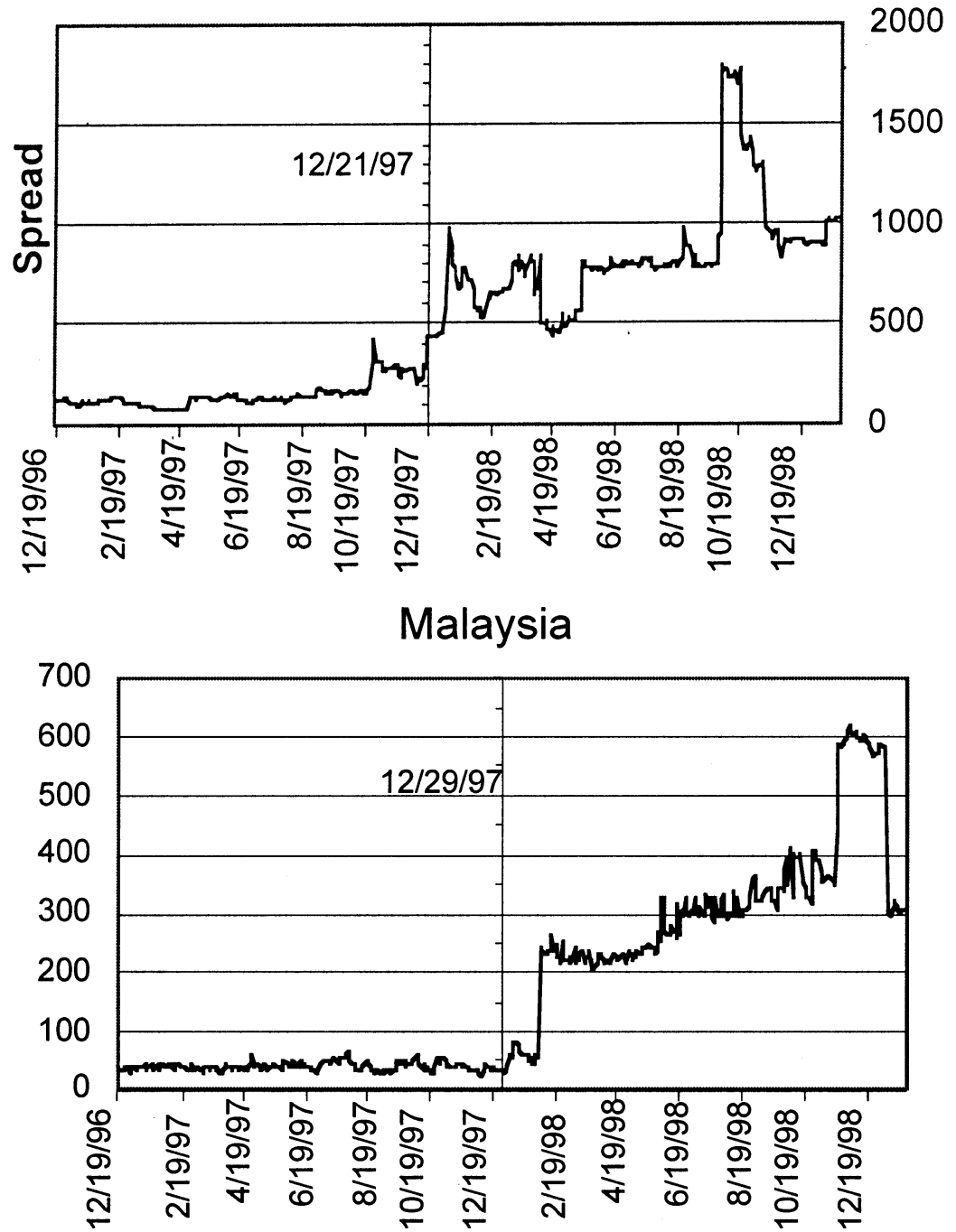

Figure 4

rating criteria via their industry publications, e.g. Moody's $(1991,1995)$ and S\&P's (1994). In a seminal paper, based on statements of major credit rating agencies, Cantor and Packer (1996) have identified eight quantitative criteria as the determinants of the sovereign rating: per capita income, GDP growth, inflation, fiscal balance, external balance, external debt, economic develop- 


\section{Thailand}

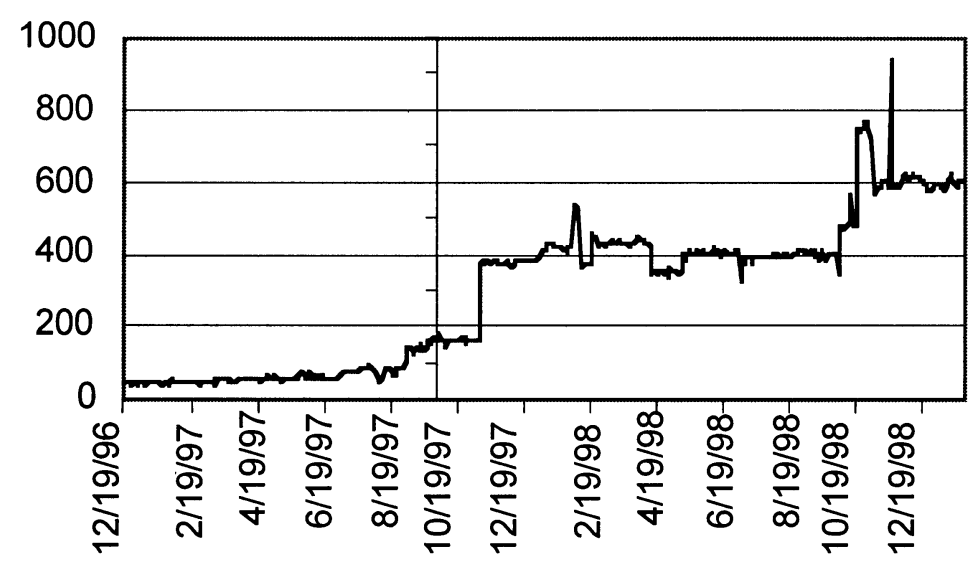

Figure 4 (continued)

ment and default history ${ }^{5}$. Indeed, in their subsequent econometric analysis, most of these variables are closely related to the ratings assigned and the predictive ability of these variables is quite impressive. The model is able to explain more than 90 per cent of the sample variation with a residual standard error of about 1.2 rating notches. While the model is useful in figuring out the basic criteria the rating industry uses, it does not, however, compare the magnitude of changes required by economic fundamentals before and after the rating changes. Therefore, it does not address the very question of whether ratings assigned have a procyclical characteristic in the event of a sovereign economic stress.

While the Cantor and Packer model may be considered as the basic sovereign credit rating model which rating agencies used before the East Asian financial crisis, the model may not have fared well after the crisis given the fact that rating agencies had all missed the symptoms of the impending economic crisis in East Asia and had been forced to be led by tumultuous economic events in Asia, rather than lead the event by forewarning investors before and during the crisis. In fact, the rating agencies have also realized the vulnerabilities of their pre-crisis models and have publicly acknowledged the problem. Fitch-IBCA, in an industry comment in January 1998, After Asia: some lessons of the crisis, points out the importance of the short-term debt associated with foreign currency lending. In the report, they also point out that other factors that were missed in their watch-list - such as total external debt

5 See Cantor and Packer (1996) for a detailed explanation on the rational of these variables used. 
including sovereign and private debt, transparency in policy and data, exchange rate regime and the competency level of policy makers during the crisis - are important factors in determining sovereign ratings. Similarly, Moody's in a subsequent statement, Outlining the major factors of country risk (Truglia, 1998), emphasizes the importance of the short-term debt. They use a new debt sustainability indicator, the ratio of current account balances plus short-term foreign currency debt over foreign exchange reserves, to measure a country's short-term foreign currency liquidity condition. Thus, it can be concluded that the important difference of the rating agencies' model after the East Asian financial crisis is perhaps to put more emphasis on short-term foreign currency debt in evaluating sovereign risk.

Rather than using quantitative model-generated ratings alone in the process of assigning ratings to sovereign countries, rating agencies also apply qualitative judgement based on a set of country specific, ad hoc, information. Therefore, the actual ratings issued by credit rating agencies can be expressed as a function of two determinant parts: ratings generated from quantitative models that reflect the sovereign country's economic fundamentals and ratings generated from ad hoc country information that reflect rating agencies' qualitative judgements. A formula with distributed weights attached to the two segments of ratings can then be expressed as follows:

$$
\begin{aligned}
& \text { Ratings }=\omega_{q} \text { Ratings }_{q}+\omega_{j} \text { Ratings }_{j} \\
& \omega_{q}+\omega_{j}=1
\end{aligned}
$$

where Ratings represents the actual ratings assigned by rating agencies; $\omega_{q}$ is a numerical weight attached to Ratings $s_{q}$ which is assumed to be generated from a quantitative model that reflects the sovereign country's economic fundamentals. $\omega_{j}$ is a weight attached to Ratings $s_{j}$ which is assumed to be generated from rating agencies' ad hoc judgement. Actual ratings are thus a weighted average of Ratings $s_{q}$ and Ratings $s_{j}$. Although what weight is attached to each determinant rating criterion is, in general, unknown to the public, the weights assigned to these criteria can nevertheless be inferred once we have the information for actual ratings assigned and we compute the quantitative model-generated ratings. For example, if the actual rating is lower than the model-generated rating from economic fundamentals, this perhaps implies that rating agencies attach a higher weight to their qualitative or idiosyncratic judgement than to the ratings generated from economic fundamentals, and vice versa. ${ }^{6}$

Thus, from the illustrative example, the strategy to discern whether credit ratings are procyclical becomes clear. We start by focusing on an econometric

${ }^{6}$ For instance, it is likely that rating agencies had looked at short-term debt even before they formally recognized the importance of this variable in their quantitative model. In such case, the decision to include this variable in their own quantitative model should have increased the weight $\omega_{q}$. 
model based on a set of criteria of sovereign countries' economic fundamentals singled out by major rating agencies, especially by Moody's. We then compare model-generated ratings with the actual ratings assigned by the rating agencies. If the ratings generated from a model of economic fundamentals are consistently higher (or lower) than the actual ratings assigned for a country, then the ratings assigned from the qualitative judgement part tend to undermine (or overstate) the ratings generated by the economic fundamentals and, thus, they clearly indicate that rating agencies tend to use their idiosyncratic judgement to modify the ratings generated by the economic fundamentals. In doing so, rating agencies may behave in a manner that may potentially generate procyclical sovereign ratings. This could happen during a systemic economic crisis. If rating agencies did not forewarn investors about possible sovereign risks before the crisis, one of the indications could be that they tended to assign ratings above the ratings predicted by the economic fundamentals. However, as an economic crisis occurs, they tend to overly downgrade sovereign ratings so as to protect their reputation capital. Such a sovereign rating pattern indicates that rating agencies might have exacerbated the already worsening economic fundamentals by hastening capital outflows and causing future capital inflows to evaporate. Should such an event take place, we would conclude that credit ratings have a procyclical effect on a country that is in an economic turmoil.

\subsection{Ratings Based on Economic Fundamentals before and after the East Asian Crisis}

We present two quantitative models in this section: Based on Cantor and Packer (1996), the first model is drawn from a set of rating criteria before the current East Asian financial crisis. The second model is based on comments made by the rating agencies after the East Asian financial crisis and includes short-term debt, in addition to traditional explanatory variables. The sample includes 17 countries for a time period of ten years: 1989 to 1998. The sample countries are Argentina, Australia, Brazil, China, Greece, Hungary, Iceland, India, Indonesia, Korea, Malaysia, Mexico, New Zealand, the Philippines, Portugal, Thailand, and Venezuela. Note that whether a country is selected in this sample depends on data availability for the country. The yearly ratings are the minimum ratings of the year and they are taken from publications of Moody's Investor's Service.

We present results obtained by using both a linear and a nonlinear calculated on the basis of the turbulent period (November-December 1997) spreads - numeric cardinalization of graded rating notches. We apply the random effect estimation methodology to adjust for possible correlation among cross-section effects and for possible auto-correlation existed in the 10- 
year time series data. ${ }^{7}$ The regression results are presented in Table 3 and Table 4.

The regression results indicated in the pre-crisis model show that all explanatory variables have the expected signs and most of them are significant,

Table 3: Linear Numerical Conversion Regression Results

\begin{tabular}{lcc}
\hline & $\begin{array}{c}\text { Credit rating agencies' } \\
\text { model before the } \\
\text { crisis }\end{array}$ & $\begin{array}{c}\text { Credit rating agencies' } \\
\text { model after the } \\
\text { crisis }\end{array}$ \\
\hline Independent variables & $\begin{array}{c}\text { Dependent variable: Rating } \\
\text { Constant }\end{array}$ & $\begin{array}{c}\text { Dependent variable: Rating } \\
51.2(14.2)^{*}\end{array}$ \\
GDP per capita & $0.0002(0.5)$ & $0.0001(0.2)$ \\
Real GDP growth & $31.2(4.1)^{*}$ & $28.6(3.7)^{*}$ \\
Inflation rate & $-0.001(-1.1)$ & $0.0001(0.1)$ \\
Budget deficit & $-0.4(-2.0)^{* *}$ & $-0.4(-2.2)^{* *}$ \\
Current account balances (CAB) & $-0.5(-2.7)^{*}$ & $-0.6(-3.1)^{*}$ \\
Development indicator & $5.2(3.4)^{*}$ & $6.3(4.2)^{*}$ \\
External debt & $-0.0001(-1.7)^{* * *}$ & \\
(CAB + short-term debt)/Foreign & & $-2.0(-2.8)^{*}$ \\
$\quad$ exchange reserves & & \\
$\mathrm{R}^{2}$ & 0.30 & 0.33 \\
\hline
\end{tabular}

Note: Numbers in parentheses are t statistics.

Star signs $*, * *, * * *$ indicate 99,95 , and 90 per cent significance level, respectively.

The sample size is 161 .

The development indicator is one if the country is a member of the OECD and zero otherwise.

Data Source: Moody's Investor's Service, World Bank, and IMF.

Table 4: Nonlinear Numerical Conversion Regression Results

\begin{tabular}{|c|c|c|}
\hline & $\begin{array}{l}\text { Credit rating agencies' } \\
\text { model before } \\
\text { the crisis }\end{array}$ & $\begin{array}{c}\text { Credit rating agencies' } \\
\text { model after } \\
\text { the crisis }\end{array}$ \\
\hline Independent variables & Dependent variable: Rating & Dependent variable: Rating \\
\hline Constant & $63.2(11.7)^{*}$ & $61.8(12.0)^{*}$ \\
\hline GDP per capita & $-0.0003(-0.5)$ & $-0.0006(-0.9)$ \\
\hline Real GDP growth & $40.0(3.5)^{*}$ & $35.3(3.2)^{*}$ \\
\hline Inflation rate & $-0.003(-1.4)$ & $-0.0001(-0.1)$ \\
\hline Budget deficit & $-0.3(-1.1)$ & $-0.3(-1.2)$ \\
\hline Current account balances (CAB) & $-0.7(-2.3)^{* *}$ & $-0.8(-2.7)^{*}$ \\
\hline Development indicator & $7.3(3.2)^{*}$ & $8.2(3.8)^{*}$ \\
\hline External debt & $-0.0001(-1.87)^{* * *}$ & \\
\hline $\begin{array}{l}(\mathrm{CAB}+\text { short-term debt }) / \text { Foreign } \\
\text { exchange reserves }\end{array}$ & & $-3.3(-3.2)^{*}$ \\
\hline $\mathrm{R}^{2}$ & 0.22 & 0.25 \\
\hline
\end{tabular}

Note: Numbers in parentheses are t statistics. Star signs ***,*** indicate 99,95 , and 90 percent significance level, respectively.

Sample size is 161 .

Development indicator is defined as whether a country is in OECD.

Data Source: Moody's Investor's Service, World Bank, and IMF.

7 This is because the exact small sample properties of these estimators are not known. In some instances, the small sample OLS results are comparable to that adjusted for cross-section effect. A Breush-Pagan test may provide some guidance.

(C) Banca Monte dei Paschi di Siena SpA, 1999. 
the only exceptions being GDP per capita and the inflation rate. Similarly, after replacing external debt with a short-term sovereign liquidity indicator - which is defined as the ratio of current account balance plus short-term debt over the country's foreign exchange reserves - most of the explanatory variables are still statistically significant, again with the exception of GDP per capita and the inflation rate. In particular, the short-term debt measure is negatively and significantly correlated with sovereign ratings.

Regression results on the nonlinear cardinalization are presented in Table 4. As expected, the results do not change much, except for two of the explanatory variables. Though it is not statistically significant, the sign of GDP per capita changes to negative in both the pre- and post-crisis models. Budget deficit, though still negatively correlated with ratings, is no longer significant. In addition, $R^{2}$ for pre- and post-crisis models have dropped from 0.30 and 0.33 to 0.22 and 0.25 , respectively, largely due to the effect of nonlinear credit rating cardinalization.

\subsection{Are Credit Ratings Procyclical? Evidence from East Asia}

We use coefficients generated in Tables 3 and 4 to calibrate the predicted ratings before and after the financial crisis in Asia for pre- and post-crisis rating models using both linear and nonlinear cardinalization methods. Modelpredicted ratings are then compared with actual ratings assigned by rating agencies. Evidence for four East Asian countries is presented in Figures 5 and 6 for the linear rating conversion and in Figures 7 and 8 for the nonlinear rating conversion.

Two interesting features stand out from Figures 5 and 6 . First, before the East Asian financial crisis, the actual ratings assigned to the four high-growth dynamic East Asian economies were consistently higher than the economic fundamentals would warrant. The second feature is that after the crisis, the actual ratings dropped much more sharply than the model-predicted ratings, suggesting that rating downgrades were larger than the economic fundamentals would warrant.

In the case of Korea and Thailand, in Figures 5 and 6, for example, the actual ratings fell sharply from 80 (A1) and 75 (A2) to 50 (Ba1) at the end of 1997. Before the crisis, the actual ratings were ten points higher than modelpredicted ratings in Korea. They were about five to ten points higher in Thailand. It is apparent that rating agencies attached higher weights to their qualitative judgement than they gave to the economic fundamentals both in pre- and post-crisis rating assignment, thereby exhibiting a pattern that when the economy is booming, economic fundamentals are ignored and when the economy is deteriorating, economic fundamentals are also disregarded. Modelgenerated ratings are closely followed by actual ratings until 1996 for Malaysia and 1997 for Indonesia in both pre- and post-crisis models.

It is important to emphasize that, according to both the pre- and post-crisis 
Indonesia: Actual Ratings V.S. Model-predicted Ratings

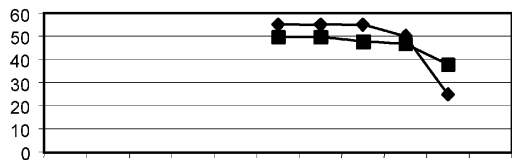

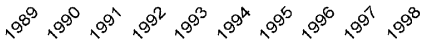

$\multimap$ Actual $\multimap$ Model-predicted

Malaysia: Actual Ratings V.S. Model-predicted Ratings

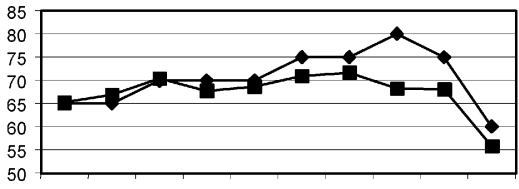

1989199019911992199319941995199619971998

Actual $\rightarrow$ Model-predicted
Korea: Actual Ratings V.S. Model-predicted Ratings

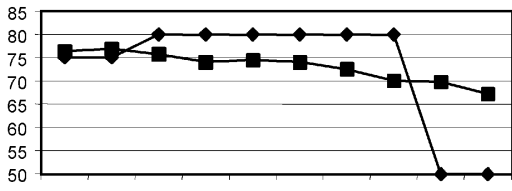

1989199019911992199319941995199619971998

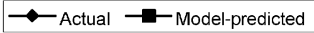

Thailand: Actual Ratings V.S. Model-predicted Ratings

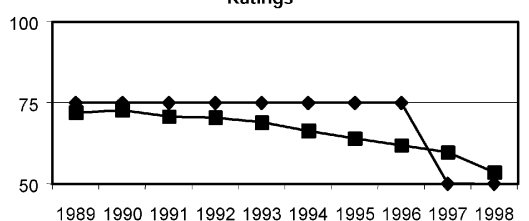

1989199019911992199319941995199619971998

$\rightarrow$ Actual $\rightarrow$ Model-predicted

Figure 5: Actual Ratings vs Model-Predicted Ratings (Pre-Crisis Model: Linear Conversion)

Indonesia: Actual Ratings V.S. Model-predicted Ratings

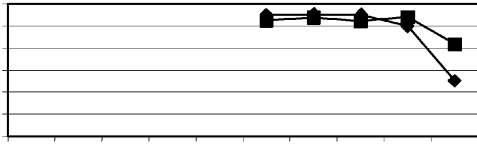

1989199019911992199319941995199619971998

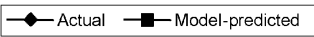

Malaysia: Actual Ratings V.S. Model-predicted Ratings

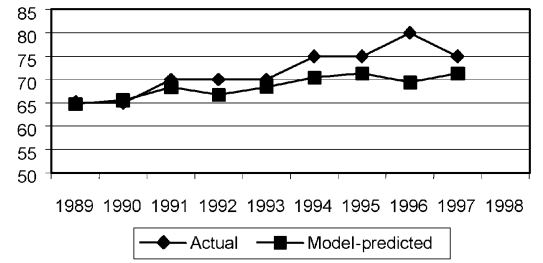

Korea: Actual Ratings V.S. Model-predicted Ratings

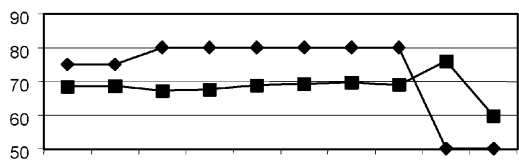

1989199019911992199319941995199619971998

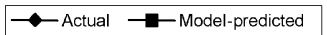

Thailand: Actual Ratings V.S. Model-predicted Ratings

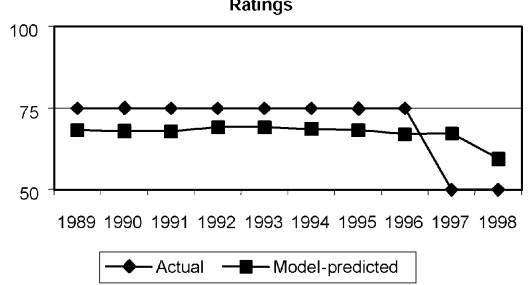

Figure 6: Actual Ratings vs Model-predicted Ratings (Post-crisis Model: Linear Conversion)

(C) Banca Monte dei Paschi di Siena SpA, 1999. 
Indonesia: Actual Ratings V.S. Model-predicted Ratings

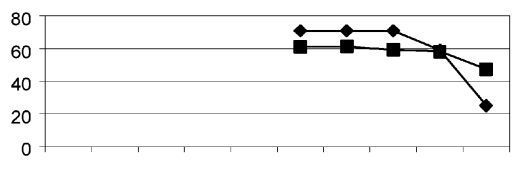

1989199019911992199319941995199619971998

$\rightarrow$-Actual $\rightarrow$-Model-predicted

Malaysia: Actual Ratings V.S. Model-predicted Ratings

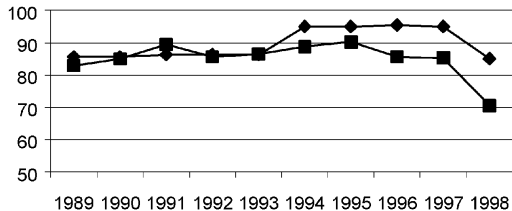

Actual
Korea: Actual Ratings V.S. Model-predicted Ratings
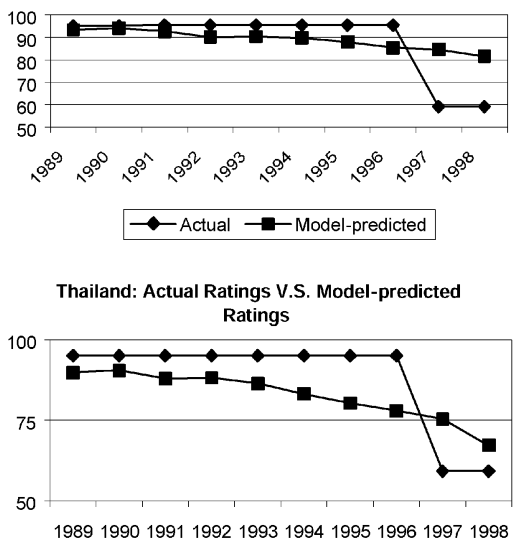

Actual $\rightarrow$-Model-predicted

Figure 7: Actual Ratings vs Model-predicted Ratings (Pre-crisis Model: Nonlinear Conversion)

Indonesia: Actual Ratings V.S. Model-predicted Ratings

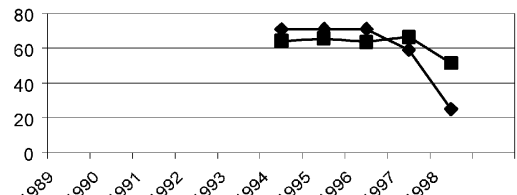

Actual

Model-predicted

Malaysia: Actual Ratings V.S. Model-predicted Ratings

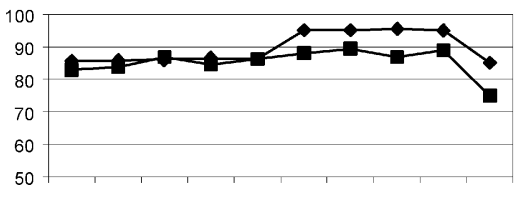

1989199019911992199319941995199619971998

$\rightarrow$ Actual $\rightarrow$-Model-predicted
Korea: Actual Ratings V.S. Model-predicted Ratings

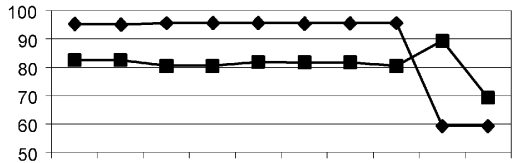

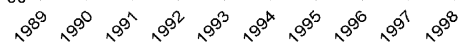

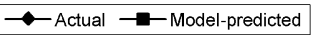

Thailand: Actual Ratings V.S. Model-predicted Ratings

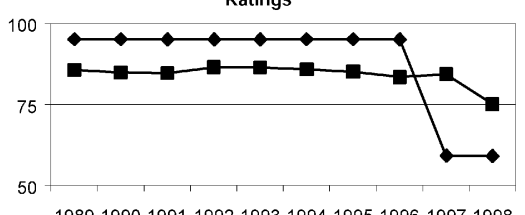

1989199019911992199319941995199619971998

Actual $\rightarrow$ Model-predicted

Figure 8: Actual Ratings vs Model-predicted Ratings (Post-crisis Model: Nonlinear Conversion)

models, neither Korea nor Thailand should ever have been assigned a belowinvestment-grade rating.

There appears to be a trend of convergence between model-generated ratings and actual ratings in 1998, a year after the financial crisis. This is, in 
fact, not difficult to explain. Since rating assignments have tremendous power to influence market expectations on a country and, to a certain extent, the ratings can affect investors' portfolio allocation decisions, they may subsequently undermine macroeconomic fundamentals of the country. As macroeconomic fundamentals of the country deteriorate, model-predicted ratings also tend to decline and thereby converge with actual ratings, though with a lag. Thus, we may just be observing a self-fulfilling prophecy.

Because the threshold effect between an investment grade rating and a non-investment grade rating could be large, the linearly converted sovereign ratings may not be able to capture this jump. Therefore, the nonlinear cardinalization is adopted to capture such a threshold effect. This becomes a critical robustness test in helping to determine whether the procyclical effect observed in the linear rating conversion case still holds.

Figures 6 and 7 present results for the pre-crisis model using the nonlinear cardinalization method calibrated on the turbulent period (November-December 1997). Compared with the linear rating conversion, the difference between model-generated ratings and actual ratings assigned comes out substantially similar for all countries; this is especially evident for Korea and Thailand. In spite of the trend of convergence, rating agencies have consistently excessively downgraded ratings for Korea. As exhibited in the linear rating conversion case, the model-predicted ratings also tend to decrease after the macroeconomic fundamentals have significantly deteriorated, therefore accelerating convergence.

\section{Why are Credit Ratings Procyclical?}

Although there may be more than one explanation to this question, we will argue that credit ratings are procyclical because of the reputation incentives faced by rating agencies. Specifically, credit rating agencies depend on their reputation capital and, if their reputation capital fluctuates procyclically, they may have an incentive to set ratings procyclically.

In one of the few models dealing with the issue of rating agencies, Millon and Thakor (1985) demonstrate that information gathering agencies (rating agencies) may arise in a world of informational asymmetries and moral hazard. According to them, in a setting in which true firm values are certified by screening agents whose payoffs depend on noisy ex post monitors of information quality, the formation of information gathering agencies is justified for two reasons: it enables screening agents to diversify their risky payoffs; and it allows information sharing.

However, Millon and Thakor (1985) assume perfect knowledge by the information gathering agency about the underlying risk of the borrower and do not model the possibility that investors may wish to verify ex post the quality of the information provided by rating agencies. 
In a more general setup, one would like to model the effort of and the payoffs to the rating agency. ${ }^{8}$ Specifically, it is likely that rating agencies' payoffs worsen when these agencies' reputation capital is lowered. If we consider that rating agencies' reputation capital suffered as a result of their poor performance as the East Asian crisis unfolded, then it seems reasonable to hold that rating agencies had an incentive to become more conservative so as to rebuild their reputation capital.

Whereas this argument would explain why rating agencies may have an incentive to become more conservative after a major crisis has caught them by surprise, a similar reasoning would account for rating agencies' incentive to be less conservative during an expansionary period. In fact, during an expansionary period, these agencies' reputation capital is likely to be high. Thus, rating agencies do not need to worry about rebuilding their reputation and can indulge in more lenient rating assignments. ${ }^{9}$

\section{Conclusion}

In this paper, we demonstrated that the procyclical nature of rating agencies' sovereign ratings may have contributed to aggravate the East Asian financial crisis. The results from our econometric model illustrate that rating agencies attached higher weights to their qualitative judgement than to the economic fundamentals both reflected in their pre-crisis ratings and post-crisis rating downgrades, thereby exhibiting procyclical nature of rating assignment. Ultimately, such behaviour may have helped to exacerbate the boom and bust cycle in East Asia. We also propose an endogenous rationale to explain why rating agencies became excessively conservative after having made blatant mistakes in predicting the East Asian crisis. Specifically, rating agencies would have an incentive to become more conservative so as to recover from the damage these mistakes caused to them and to rebuild their own reputation capital.

It has long been noted that financial markets often seemed characterized by herd behaviour, especially in times of panic. Such behaviour can be interpreted in terms of rational behaviour with asymmetric information, in terms of rational (or irrational) sunspot equilibria, and in terms of compensation schemes based on relative performance. Credit rating agencies provide a coordinating mechanism which may exacerbate these phenomena. As such, they have a special responsibility not to set off or exacerbate financial crises.

\footnotetext{
${ }^{8}$ For instance, Kuhner (1999) argues that, in a systemic crisis, their payoffs may lead rating agencies to an equilibrium in which they pool 'good' borrowers together with 'bad' borrowers.

9 An alternative 'explanation' of the incentives facing rating agencies might run along the following lines. Suppose investors worry more about large losses than about overall accuracy, and that large down-side mistakes are more 'salient' - that is, more likely to be noticed and thus to damage reputation. Then, the credit rating agencies have an incentive to provide biased estimates, estimates which are less likely to err by being overly optimistic.
} 
This paper has raised questions about how they have lived up to that responsibility.

This research can be extended in two important dimensions: Theoretically, able to empirical evidence, it would be interesting to build a formal model able to capture the procyclical nature of sovereign credit ratings. Empirically, the current study only focuses on the aspect that ratings are determined by economic fundamentals. Another important aspect, which is ignored in this paper, is that, under certain circumstances, especially in an economic panic, credit ratings can also affect economic fundamentals in a detrimental way that can aggravate the downward spiral of an economic crisis. 


\section{REFERENCES}

BIS (BAnk for International Settlements) (1998), Annual Report, Basle, June.

R. CAntor - F. PACKer (1994), “The Credit Rating Industry”, Federal Reserve Bank of New York Quarterly Review, Summer-Fall, pp. 1-26.

R. CANTOR - F. PACKer (1996), "Determinants and Impact of Sovereign Credit Ratings", Federal Reserve Bank of New York Quarterly Review, October, pp. 3751.

R. Cantor - F. Packer (1997), "Differences of Opinion and Selection Bias in the Credit Rating Industry”, Journal of Banking and Finance, 21, pp. 1395-417.

R. S. Dale - S. H. Thomas (1991), "The Regulatory Use of Credit Ratings in International Financial Markets", Journal of International Securities Markets, 5(2), Spring, pp. 9-18.

FitCH-IBCA (1998), “After Asia: Some Lessons of the Crisis”, Fitch-IBCA Sovereign Comment, January 13.

J. R. M. Hand - R. W. Holthausen - R. W. Leftwich (1992), "The effect of bond rating agency announcements on bond and stock prices", The Journal of Finance, 47, pp. 733-52.

IMF (1998), Capital World Economic Outlook and International Capital Markets. Interim Assessment, Washington DC, December.

C. Kunner (1999), Rating Agencies: Are They Credible? - Insights into the Reporting Incentives of Rating Agencies in Times of Enhanced Systemic Risk, University of Munich, mimeo.

M. H. Millon - A. V. Thakor (1985), "Moral Hazard and Information Sharing: A Model of Financial Information Gathering Agencies", The Journal of Finance, 40, pp. 1403-22.

Moody's InVestment Service (1991) Global Analysis. London: IFR Publishing.

Moody's Investment Service (1994), "Note to the SEC on the Disclosure of Security Ratings", Moody's Investor Service, December 5.

Moody's Investment Service (1995) Sovereign Supranationals Credit Opinions, September.

H. Reisen - J. von Maltzan (1999), "Boom and Bust and Sovereign Ratings", Organisation for Economic Co-operation and Development, Development Centre, Technical Papers (International) No. 148, June, pp. 1-23.

S\&P (STANDARD AND PoOR) (1994) "Sovereign Rating Criteria", Emerging Markets, October, pp. 124-27.

V. TRuglia (1998), "Outlining the Major Factors of Country Risk", Moody's Investor Service, April.

World BAnk (1998), East Asia: Road to Recovery, World Bank, November.

(C) Banca Monte dei Paschi di Siena SpA, 1999. 
Copyright of Economic Notes is the property of Wiley-Blackwell and its content may not be copied or emailed to multiple sites or posted to a listserv without the copyright holder's express written permission. However, users may print, download, or email articles for individual use. 